\title{
Effect of Plant Growth Promoting Bacteria on Seed Germination, Seedling Vigor and Growth Lagenaria siceraria (Molina) Standl
}

\author{
Navdeep Singh* and Daljeet Singh \\ Vegetable Department, University College of Agriculture, Guru Kashi University, \\ Talwandi Sabo (Punjab), India \\ *Corresponding author
}

Ke y w o r d s
Serratia
marcescens,
Bacillus subtilis,
PGPR and bottle
gourd

\section{A B S T R A C T}

\section{Introduction}

Bottle gourd [Lagenaria siceraria (Molina) Standl] is a vital cucurbitaceous crop grown for its fleshy fruits in tropical and subtropical regions (Desai et al., 2016). It's probably originated in Africa. Bottle gourd young fruits are edible, but the mature hollowed shells used as bottles, musical instruments, and floats for fishermen. Bottle gourd fruit crush is employed within the treatment of insanity, epilepsy, and other nervous diseases. Bottle 
gourd plant is an annual herb and vigorous running vine. Stems of bottle gourd are suclate angular, the leaf is simple, suborbicular non-lobed or slightly lobed; flowers white, monoecious, and axillary; fruits are berry, varies in size, and shape, woody when mature. Bottle gourd area in India was 186 million hectares and production are 3052 '000' million tonnes during 2018-2019 (Agricultural statistics, 2019). The mechanisms by which PGPRs promote plant growth aren't fully understood. But, several mechanisms are suggested by which PGPR can enhanced stress resistance, symbiotic N2 fixation according to Salantur et al., (2006), solubilization of phosphate, and mineralization of organic phosphate or other nutrients (Cattelan et al., 1999; Jeon et al., 2003), increasing the availability or availability of primary nutrients to the host plant and antagonism against phytopathogenic microorganisms by the production of siderophores, synthesis of antibiotics, enzymes or fungicidal compounds and competition with detrimental microorganisms (Ashrafi et al., 2011; Wu et al., 2005; Lucy et al., 2004; Ahmad et al., 2005; Egamberdiyeva et al., 2007).According to Dursun et al., (2019) the seedsof tomato cultivars treated with three different concentrations $(1,3$, and 5 gL-1 and control i.e. un-inoculated) and two different bacterial fertilizers including Azotobacter spp. $(1 \times 109 \mathrm{CFU})$, and a mixture of Bacillus subtilis and Bacillus megatarium $(1 \times 109$ UFC). The effects of these treatments were found significant in plant growth parameters. Bacterial fertilization increased yield and other parameters in all treatments of tomato. Kumar et al., (2017) studied that the effect of Enterobacter, M. arborescens and Serratia marcescens on yield and nutrient uptake of wheat and suggested that consortium of two or three isolates significantly increased plant height $(13.91 \%$, $34.32 \%)$, straw yield $(78.58 \%, 26.23 \%)$ and grain yield $(79.83 \%, 24.05 \%)$ in pot and field experiment respectively and uptake of nutrients such as $\mathrm{N}$ by $50.64 \%$ and $\mathrm{P}$ by $56.49 \%$ was also enhanced by wheat in field conditions was also observed. Singh et al., (2017) suggested that Pseudomonas (RS1) and Bacillus (R7) most dominant in the rhizosphere of bitter melon and Bacillus (R7) may be used as a biofertilizer for bitter melon growth. However, scanty information is out there regarding the utilization of bio-priming in several crops and it must be investigated. Keeping in sight the above facts this investigation is going to be undertaken to review the effect of plant growth-promoting bacteria on seed germination, seedling vigor and growth of Lagenaria siceraria (Molina) Standl. with the objectives to evaluate the effect of plant growth-promoting bacteria on seed germination, seedling vigor and growth of bottle gourd.

\section{Materials and Methods}

The present investigation entitled "Effect of plant growth-promoting bacteria on seed germination, seedling vigour and growth of Lagenaria siceraria (Molina) Standl." was conducted during Kharif season of 2019 and 2020 at the University College of Agriculture farm, Talwandi Sabo, Bathinda (Punjab) and experiment was laid out by Randomized Block Design with three replications. Three standard PGPR strains these included Serratia marcescens MTCC 10241 and Bacillus subtilis MTCC7611; MTCC814 were obtained from Microbial Type Culture Collection (MTCC) Chandigarh, India.

\section{Sub culturing of bacterial culture}

The bacterial culture was sub cultured by growing in nutrient broth and centrifuged at $120 \mathrm{rpm}$ for $24 \mathrm{hrs}$. Spectrophotometer at "600" nm light was used to check the growth of bacteria optical density. 


\section{Sterilization and inoculation of seeds}

The seeds of bottle gourd was surface sterilized with $\mathrm{NaOCl}$ for 2 minutes, and after that wash thoroughly with sterile distilled water for three times. Then surface sterilizes seeds was soaked into bacterial suspension at a particular concentration and they were allowed for overnight. The seeds were soaked in sterile distilled water was used as control.

\section{Preparation of pots and treatment details}

The soil was sterilized with formalin @ $\mathrm{g} / \mathrm{m}^{3}$ before two weeks of transplanting. Polybags with a capacity of $10 \mathrm{~kg}$ are filled with mixture formalin sterilized coarse sandy loam soil and treatedseeds of bottle gourd variety Punjab Bahar were sown. The poly-bags were arranged according to the recommended spacing in the open field. Total treatments are seven and these were $\mathrm{T}_{1}$ : Control (Water soaked), $\mathrm{T}_{2}$ : Fertilizer $100 \%+$ Serratia marcescens MTCC $10241+$ Bacillus subtilis MTCC7611 + Bacillus subtilis MTCC8141, $\mathrm{T}_{3}$ : Fertilizer $50 \%$ +Serratia marcescens MTCC 10241 + Bacillus subtilis MTCC7611 + Bacillus subtilis MTCC8141, $\mathrm{T}_{4}$ : Serratia marcescens MTCC $10241+$ Bacillus subtilis MTCC7611 + Bacillus subtilis MTCC8141, $\mathrm{T}_{5}$ : Serratia marcescens MTCC 10241, $\mathrm{T}_{6}$ : Bacillus subtilis MTCC8141, $\mathrm{T}_{7}$ : Bacillus subtilis MTCC761.

\section{Details of observations recorded}

Seed germination percentage was analysed by using the formula: Seed Germination \%= Germinated seeds / Total Seed Sown $\times 100$, Seed vigour was measured by using formula: Seedling length $\times \%$ germination, Vine length $(\mathrm{cm}$.), Number of primary branches per vine (No.), Number of nodes on the main axis (No.), Number of leaves (No.), Leaf area $\left(\mathrm{cm}^{2}\right)$ and Days to first fruit set (No.) are parameters observed during field trail in the
2019 and 2020 kharif season.

\section{Statistical analysis}

All data were analysed for different characters with the help of OPSTAT (Sheoran et al., 1998). The critical difference at 5\% level of implication was calculated to equate the mean different treatments.

\section{Results and Discussion}

The data in table 1 shows that treatment $\mathrm{T}_{2}$ (RDF $100 \%+$ Serratia marcescens MTCC $10241+$ Bacillus subtilis MTCC7611 + Bacillus subtilis MTCC814) had the significant results in seed germination percentage $(89.27 \%)$ in 2019 and $(88.85 \%)$ in 2020 years of experimentation. And it was followed by $\mathrm{T}_{3}$ (RDF $50 \%+$ Serratia marcescens MTCC $10241+$ Bacillus subtilis MTCC7611 + Bacillus subtilis MTCC814), the seed germination percentage was $86.92 \%$ in 2019 and $85.61 \%$ in the 2020. Seedling vigor significantly higher in 2019 (2050.89) and in 2020 (2048.17) by $\mathrm{T}_{2}$ (RDF $100 \%+$ Serratia marcescens MTCC $10241+$ Bacillus subtilis MTCC7611 + Bacillus subtilis MTCC814) treatment and it was followed by $\mathrm{T}_{3}$ (RDF $50 \%+$ Serratia marcescens $\mathrm{MTCC}$ $10241+$ Bacillus subtilis MTCC7611 + Bacillus subtilis MTCC814) treatment in both 2019 (1932.76) and in 2020 (2025.43) years.

The table 2 revealed that $\mathrm{T}_{3}$ (RDF $50 \%+$ Serratia marcescens MTCC $10241+$ Bacillus subtilis MTCC7611 + Bacillus subtilis MTCC814) treatment shows the significant result of vein length in both $2019(253.51 \mathrm{~cm})$ and $2020(251.51 \mathrm{~cm})$ years and followed by treatment $\mathrm{T}_{2}$ (RDF $100 \%+$ Serratia marcescens MTCC $10241+$ Bacillus subtilis MTCC7611 + Bacillus subtilis MTCC814) in both years. The observation was $248.76 \mathrm{~cm}$ vein length in 2019 and $246.61 \mathrm{~cm}$ in the 2020.Treatment $\mathrm{T}_{3}$ (RDF $50 \%+$ Serratia 
marcescens MTCC 10241 + Bacillus subtilis MTCC7611 + Bacillus subtilis MTCC814) shows the significant result in the number of primary branches per plant of bottle gourd crop in both 2019 (4.73) and 2020 (4.47) years and it was followed by treatment $\mathrm{T}_{2}$ (RDF $100 \%$ + Serratia marcescens MTCC $10241+$ Bacillus subtilis MTCC7611 + Bacillus subtilis MTCC814) in 2019 the number of primary branches per plant was 4.24 and 4.04 number of primary branches per plant in the year 2020 .

The table 3 shows that the number of nodes on the main axis significantly maximum in treatment $\mathrm{T}_{3}(\mathrm{RDF} 50 \%+$ Serratia marcescens MTCC $10241+$ Bacillus subtilis MTCC7611 + Bacillus subtilis MTCC814) in 2019 (21.33) and the 2020 year observation was same as in 2019 and followed by $\mathrm{T}_{2}$ treatment with observation 19.46. Treatment $\mathrm{T}_{2}$ (RDF $100 \%+$ Serratia marcescens MTCC $10241+$ Bacillus subtilis MTCC7611 + Bacillus subtilis MTCC814) and $\mathrm{T}_{4}$ (Serratia marcescens MTCC 10241 + Bacillus subtilis MTCC7611 + Bacillus subtilis MTCC814) was at par with each other and followed the $\mathrm{T}_{3}$ treatment in the 2020 year. Maximum number of leaves per plant 32.38 were found in the treatment $\mathrm{T}_{3}$ (RDF $50 \%$ +Serratia marcescens MTCC10241 + Bacillus subtilis MTCC7611 + Bacillus subtilis MTCC814) and followed by treatment $\mathrm{T}_{2}$ (RDF $100 \%$ +Serratia marcescens MTCC10241+ Bacillus subtilis MTCC7611 + Bacillus subtilis MTCC814) with observation 30.13 in the 2019 year. A maximum number of leaves per plant 30.90 are reported in the 2020 year in by $\mathrm{T}_{3}$ (RDF $50 \%+$ Serratia marcescens MTCC10241 + Bacillus subtilis MTCC7611 + Bacillus subtilis MTCC814) treatment and followed by $\mathrm{T}_{2}$ (RDF $100 \%+$ Serratia marcescens MTCC10241 + Bacillus subtilis
MTCC7611 + Bacillus subtilis MTCC814) treatment with 28.43 number of leaves per plant and it was at par with 27.30 number of leaves per plant by $\mathrm{T}_{4}$ Serratia marcescens MTCC10241 + Bacillus subtilis MTCC7611 + Bacillus subtilis MTCC814) treatment.

The table 4 shows that maximum leaf area $187.99 \mathrm{~cm}^{2}$ were found in the treatment $T_{3}$ (RDF $50 \%+$ Serratia marcescens MTCC10241 + Bacillus subtilis MTCC7611 + Bacillus subtilis MTCC814) and followed by treatment $\mathrm{T}_{2}$ (RDF $100 \%$ +Serratia marcescens MTCC10241 + Bacillus subtilis MTCC7611 + Bacillus subtilis MTCC814) with observation of leaf area $182.60 \mathrm{~cm}^{2}$ in 2019 year. Maximum leaf area $187.25 \mathrm{~cm}^{2}$ are reported in 2020 year in by $\mathrm{T}_{3}$ (RDF $50 \%$ + Serratia marcescens MTCC10241 + Bacillus subtilis MTCC7611 + Bacillus subtilis MTCC814) treatment and followed by $\mathrm{T}_{2} \quad$ (RDF $100 \%$ +Serratia marcescens MTCC10241 + Bacillus subtilis MTCC7611 + Bacillus subtilis MTCC814) treatment with 182. $45 \mathrm{~cm}^{2}$ leaf area. The days to first fruit set (48.32) were found significantly reduced in the treatment $\mathrm{T}_{3}$ (RDF $50 \%$ +Serratia marcescens MTCC10241 + Bacillus subtilis MTCC7611 + Bacillus subtilis MTCC814) and followed by treatment $\mathrm{T}_{2}$ (RDF $100 \%$ +Serratia marcescens MTCC10241 + Bacillus subtilis MTCC7611 + Bacillus subtilis MTCC814) with observation 50.66 days to first fruit set in the 2019 year. Day to first fruit set (37.90 days) are reported in the 2020 year in by $\mathrm{T}_{3}$ (RDF $50 \%$ +Serratia marcescens MTCC10241 + Bacillus subtilis MTCC7611 + Bacillus subtilis MTCC814) treatment and it was at par with $\mathrm{T}_{2}$ (RDF $100 \%$ +Serratia marcescens MTCC10241 + Bacillus subtilis MTCC7611 + Bacillus subtilis MTCC814) treatment with 49 days to first fruit set. 
Table.1 Effect of plant growth-promoting bacteria on seed germination percentage and seedling vigor of Lagenaria siceraria (Molina) Standl

\begin{tabular}{|c|c|c|c|c|c|c|}
\hline Parameter & \multicolumn{3}{|c|}{ Seed germination percentage } & \multicolumn{3}{|c|}{ Seedling vigor } \\
\hline Treatments & $\mathbf{2 0 1 9}$ & $\mathbf{2 0 2 0}$ & Pooled & $\mathbf{2 0 1 9}$ & $\mathbf{2 0 2 0}$ & Pooled \\
\hline $\mathbf{T}_{\mathbf{1}}$ & 63.00 & 61.5 & 62.25 & 1006.48 & 1005.63 & 1006.06 \\
\hline $\mathbf{T}_{\mathbf{2}}$ & 89.09 & 88.61 & 88.85 & 2050.89 & 2048.17 & 2049.53 \\
\hline $\mathbf{T}_{\mathbf{3}}$ & 86.92 & 85.70 & 86.31 & 1932.76 & 2025.43 & 1979.10 \\
\hline $\mathbf{T}_{\mathbf{4}}$ & 71.01 & 70.73 & 70.87 & 1414.79 & 1446.20 & 1430.50 \\
\hline $\mathbf{T}_{\mathbf{5}}$ & 61.19 & 60.48 & 60.83 & 1047.33 & 1036.00 & 1041.67 \\
\hline $\mathbf{T}_{\mathbf{6}}$ & 58.51 & 63.43 & 60.97 & 1028.11 & 1031.90 & 1030.01 \\
\hline $\mathbf{T}_{\mathbf{7}}$ & 63.67 & 64.41 & 64.04 & 1281.53 & 1180.57 & 1231.05 \\
\hline $\mathbf{C D}(\mathbf{0 . 0 5})$ & 1.06 & 0.92 & 1.54 & 0.76 & 4.31 & 3.41 \\
\hline
\end{tabular}

Table.2 Effect of plant growth-promoting bacteria on vine length and number of primary branches per vein of Lagenaria siceraria (Molina) Standl

\begin{tabular}{|c|c|c|c|c|c|c|}
\hline Parameter & \multicolumn{3}{|c|}{ Vein length (cm) } & \multicolumn{3}{c|}{ Number of primary branches per } \\
& \multicolumn{3}{|c|}{} & & \multicolumn{3}{|c|}{ vein (No.) } & \\
\hline Treatments & $\mathbf{2 0 1 9}$ & $\mathbf{2 0 2 0}$ & Pooled & $\mathbf{2 0 1 9}$ & $\mathbf{2 0 2 0}$ & Pooled \\
\hline $\mathbf{T}_{\mathbf{1}}$ & 166.33 & 165.05 & 165.69 & 3.24 & 2.30 & 2.77 \\
\hline $\mathbf{T}_{\mathbf{2}}$ & 248.76 & 246.61 & 247.69 & 4.24 & 4.04 & 4.14 \\
\hline $\mathbf{T}_{\mathbf{3}}$ & 253.51 & 251.60 & 252.56 & 4.73 & 4.47 & 4.60 \\
\hline $\mathbf{T}_{\mathbf{4}}$ & 240.69 & 243.85 & 242.27 & 3.66 & 3.92 & 3.79 \\
\hline $\mathbf{T}_{\mathbf{5}}$ & 180.96 & 179.09 & 180.02 & 3.27 & 3.27 & 3.27 \\
\hline $\mathbf{T}_{\mathbf{6}}$ & 210.58 & 194.01 & 192.31 & 3.35 & 3.58 & 3.47 \\
\hline $\mathbf{T}_{\mathbf{7}}$ & 190.61 & 207.16 & 208.87 & 3.44 & 3.37 & 3.40 \\
\hline $\mathbf{C D}(\mathbf{0 . 0 5})$ & 0.62 & 4.09 & 2.45 & 0.07 & 0.10 & 0.26 \\
\hline
\end{tabular}

Table.3 Effect of plant growth-promoting bacteria on the number of nodes on the main axis and number of leaves of Lagenaria siceraria (Molina) Standl

\begin{tabular}{|c|c|c|c|c|c|c|}
\hline Parameter & \multicolumn{3}{|c|}{$\begin{array}{c}\text { Number of nodes on the main } \\
\text { axis(No.) }\end{array}$} & \multicolumn{3}{c|}{ Number of leaves (No.) } \\
\hline Treatments & $\mathbf{2 0 1 9}$ & $\mathbf{2 0 2 0}$ & Pooled & $\mathbf{2 0 1 9}$ & $\mathbf{2 0 2 0}$ & Pooled \\
\hline $\mathbf{T}_{\mathbf{1}}$ & 16.40 & 15.40 & 15.90 & 23.14 & 22.54 & 22.84 \\
\hline $\mathbf{T}_{\mathbf{2}}$ & 19.46 & 18.33 & 18.90 & 30.13 & 28.43 & 29.28 \\
\hline $\mathbf{T}_{\mathbf{3}}$ & 21.33 & 21.33 & 21.33 & 32.38 & 30.90 & 31.64 \\
\hline $\mathbf{T}_{\mathbf{4}}$ & 18.33 & 18.00 & 18.16 & 27.13 & 27.30 & 27.21 \\
\hline $\mathbf{T}_{\mathbf{5}}$ & 16.00 & 16.00 & 16.00 & 24.43 & 23.84 & 24.14 \\
\hline $\mathbf{T}_{\mathbf{6}}$ & 15.33 & 16.66 & 16.00 & 25.31 & 24.97 & 25.14 \\
\hline $\mathbf{T}_{\mathbf{7}}$ & 17.66 & 17.66 & 17.66 & 25.90 & 25.52 & 25.71 \\
\hline $\mathbf{C D}(\mathbf{0 . 0 5})$ & 0.82 & 0.87 & 0.72 & 0.40 & 1.30 & 0.71 \\
\hline
\end{tabular}


Table.4 Effect of plant growth-promoting bacteria on leaf area and days to first fruit set of Lagenaria siceraria (Molina) Standl

\begin{tabular}{|c|c|c|c|c|c|c|}
\hline Parameter & \multicolumn{3}{|c|}{ Leaf area (cm2) } & \multicolumn{3}{c|}{ Days to first fruit set (days) } \\
\hline Treatments & $\mathbf{2 0 1 9}$ & $\mathbf{2 0 2 0}$ & Pooled & $\mathbf{2 0 1 9}$ & $\mathbf{2 0 2 0}$ & Pooled \\
\hline $\mathbf{T}_{\mathbf{1}}$ & 166.40 & 162.50 & 164.45 & 58.37 & 57.48 & 57.92 \\
\hline $\mathbf{T}_{\mathbf{2}}$ & 182.60 & 182.45 & 182.52 & 50.66 & 49.00 & 49.83 \\
\hline $\mathbf{T}_{\mathbf{3}}$ & 187.99 & 187.25 & 187.62 & 48.32 & 47.90 & 48.11 \\
\hline $\mathbf{T}_{\mathbf{4}}$ & 177.87 & 177.35 & 177.61 & 54.06 & 52.33 & 53.19 \\
\hline $\mathbf{T}_{\mathbf{5}}$ & 169.90 & 169.04 & 169.47 & 57.23 & 56.46 & 56.84 \\
\hline $\mathbf{T}_{\mathbf{6}}$ & 173.54 & 173.13 & 173.33 & 58.60 & 58.20 & 58.40 \\
\hline $\mathbf{T}_{\mathbf{7}}$ & 174.78 & 173.70 & 174.24 & 55.15 & 53.66 & 54.41 \\
\hline $\mathbf{C D}(\mathbf{0 . 0 5})$ & 2.72 & 1.89 & 1.61 & 0.51 & 1.40 & 0.72 \\
\hline
\end{tabular}

Seed germination percentage and seedling vigor

Germination percent and seedling length are the major factors for deciding the seedling vigor. In the present study, this character showed significant variation among all treatments which might be due to PGPR (Serratia marcescens MTCC $10241+$ Bacillus subtilis MTCC7611 + Bacillus subtilis MTCC814) activity. Similar results were also reported by (Prathibha and Siddalingeshwara, 2013) studied the effect on seed treatment with PGPRs such as Pseudomonas fluorescens and Bacillus subtilis significantly increased seed germination, vigor index, and nutritional quality.

Vein length and the number of primary branches per plant

These are the characters of growth which should be enhanced to get optimum yield from the crop. So, mixture of all the bacteria (Serratia marcescens MTCC $10241+$ Bacillus subtilis MTCC7611 + Bacillus subtilis MTCC814) with $50 \%$ recommended dose of fertilizer in this experiment significantly increase the vein length and the number of primary branches per plant of bottle gourd. Correspondingly Kumar et al.,
(2015) studied that seed coating with Bacillus subtilis OTPB1 and Trichoderma harzianum OTPB3 of brinjal, beans, bitter gourd, bottle gourd, cabbage, chili, carrot, cauliflower, pumpkin, ridged gourd), fruit crop (papaya in plastic trays in a glasshouse), tuber crops (potato), ginger and turmeric, a significant increase in growth parameters under greenhouse conditions and growth and yield parameters under field conditions were recorded.

\section{The number of nodes on the main axis and} number of leaves per plant

The results revealed that the $\mathrm{T}_{3}$ (RDF $50 \%$ +Serratia marcescens MTCC10241+ Bacillus subtilis MTCC7611 + Bacillus subtilis MTCC814) treatment shows significantly increase the number of nodes on the main axis in bottle gourd crop during both the years. On the contrary Kidoglu et al., (2008) studied that Pseudomonas putida, Enterobacter cloacae, Serratia marcescens, Pseudomonas fluorescens, Bacillus spp., Pseudomonas putida) significantly increases in growth of cucumber, tomato, and pepper. The data with regards to the number of leaves produced by each plant was maximum observed in the treatment $\mathrm{T}_{3}$ (RDF $50 \%$ +Serratia marcescens MTCC10241+ Bacillus subtilis MTCC7611 + Bacillus 
subtilis MTCC814) in both years. Similiarly, Y1ldırım et al., (2015), applied Bacillus pumilis and Alcaligenes piechaudii strains as seed and/or drench treatments and found increased number of leaves in cucumber.

\section{Leaf area and the days to first fruit set}

In the pooled data with regards to leaf area produced by each plant was maximum observed in the $\mathrm{T}_{3}(\mathrm{RDF} 50 \%+$ Serratia marcescens MTCC10241 + Bacillus subtilis MTCC7611 + Bacillus subtilis MTCC814) treatment in bottle gourd crop in both years. Equally Mia (2010) evaluated the effect of PGPR on banana plantlets under nitrogen-free hydroponic condition and found an increase in growth attributes such as root hair, leaf area, chlorophyll content and total biomass. In pooled data $\mathrm{T}_{3}(\mathrm{RDF} 50 \%+$ Serratia marcescens MTCC10241 + Bacillus subtilis MTCC7611 + Bacillus subtilis MTCC814) treatment was significantly superior for a reduced number of days to first fruit set in bottle gourd crop during both years of investigation. Similarly Karakurt et al., (2011) also found that $B$. subtilis OSU-142, $B$. megaterium M-3, B. cepaciai OSU-7, and $P$. putida BA-8 have great potential to increase fruit set, plant growth, and fruit quality. Present study support that use of PGPRs may enhance the seed germination, seedling vigor, and growth of bottle gourd crop under field condition. The effective PGPR strain may be recommended to farmer which may reduce the use of chemical fertilizers in cucurbit crops.

\section{References}

Agricultural statistics. 2019. Ministry of Agriculture and Farmers welfare, Directorate of economics and Statistics, New Delhi, Shri P.C. Bodh (Ed.), pp. 1138.

Ahmad, F., Ahmad, I., and Khan, M. S. 2005.
Indole acetic acid production by the indigenous isolates of Azotobacter and fluorescent Pseudmonas in the presence and absence of tryptophan.Turk. J. Biol. 29: 29-34.

Ashrafi, V., and Seiedi, M. N. 2011. Influence of different plant densities and plant growth promoting rhizobacteria (PGPR) on yield and yield attributes of Corn (Zea maize L.). Recent res. sci. technol. 3(1): 63-66.

Cattelan, A. J., Hartel, P. G., and Fuhrmann, J. J. 1999. Screening for plant growthpromoting rhizobacteria to promote early soybean growth.SSSAJ. 63: 167080.

Desai, D., Kalyanrao, Patel, B. P., Sasidharan, N. 2016. Effect of harvesting stages and post-harvest ripening on seed yield and seed quality of Bottle gourd var. ABG1. Seed Sci. Res. 44: 127-132.

Dursun, A., Yildirim, E., Turan, M., Ekinci, M., KulL, R., and Karagoz1, F. P. 2019. Determination of the Effects of Bacterial Fertilizer on Yield and Growth Parameters of Tomato.J. Agric. Sci. Technol. 21(5): 1227-1234.

Egamberdiyeva, D. 2007. The effect of plant growth promoting bacteria on growth and nutrient uptake of maize in two different soils. Appl. Soil Ecol. 36: 18489.

Jeon, J. S., Lee, S. S., Kim, H. Y., Ahn, T. S., and Song, H. G. 2003. Plant growth promotion in soil by some inoculated microorganisms. J. Microbiol. Biotechnol. 41: 271-276.

Karakurt, H., Kotan, R., Dadasoglu, F., Aslantas, R., and Sahin, F. 2011. Effects of plant growth promoting rhizobacteria on fruit set, pomological and chemical characteristics, color values, and vegetative growth of sour cherry (Prunus cerasus cv. Kutahya). Turk. J. Biol Turkish. 35: 283-291.

Kidoglu, F., Gul, A., Ozaktan, H., and Tuzel, 
Y. 2008. Effect of Rhizobacteria on Plant Growth of Different Vegetables. Acta Hortic. 801: 1471-1478.

Kumar, S. P. M., Chowdappa1, P., and Krishna, V. 2015. Development of seed coating formulation using consortium of Bacillus subtilis OTPB1 and Trichoderma harzianum OTPB3 for plant growth promotion and induction of systemic resistance in field and horticultural crops. Indian Phytopathol. 68 (1): 25-31.

Lucy, M., Reed, E., and Glick, B. R. 2004. Application of free living plant growth promoting rhizobacteria. Antonie Van Leeuwenhoek. 86(1):1-25.

Mia, M. A. B., Shamsuddin, Z. H., Wahab, Z., and Marziah, M. 2010. Effect of Plant growth promoting rhizobacterial (PGPR) inoculation on growth and nitrogen incorporation of tissue-cultured Musa plantlets under nitrogen-free hydroponics condition. AJCS. 4 (2): 8590.

Prathibha, K. S., and Siddalingeshwara, K. G. 2013. Effect of plant growth promoting Bacillus subtilis and Pseudomonas fluorescence as rhizobacteria on seed quality of sorghum. IJCMAS. 2(3): 1118.

Salantur, A., Ozturk, A., and Akten, S. 2006. Growth and yield response of spring wheat (Triticum aestivum L.) to inoculation with rhizobacteria.PSE. 52(3): 111-18.

Sheoran, O. P., Tonk, D. S., Kaushik, L. S., Hasija, R. C., and Pannu, R. S. 1998. Statistical Software Package for Agricultural Research Workers. Recent Advances in information theory, Statistics \& Computer Applications by D.S. Hooda \& R.C. Hasija Department of Mathematics Statistics, CCS HAU, Hisar, pp. 139-143.

Singh, R., Pandey, K. D., Kumar, A., and Singh, M. 2017. PGPR Isolates from the Rhizosphere of Vegetable Crop Bitter melon (Momordica charantia): Characterization and Application as Biofertilizer. IJCMAS.6(3): 1789-1802.

Wu, S. C., Cao, Z. H., Li, Z. G., Cheung, K. C., and Wong, M. H. 2005. Effects of biofertilizer containing $\mathrm{N}$-fixer, $\mathrm{P}$ and $\mathrm{K}$ solubilizers and AM fungi on maize growth: a greenhouse trial.Geoderma. 125: 155-66.

Yıldırım, E., Ekinci, M., Dursun, A., and Karagoz K. 2015. Plant GrowthPromoting Rhizobacteria Improved Seedling Growth and Quality of Cucumber (Cucumis sativus L.). International Conference on Chemical, Food and Environment Engineering, Dubai, UAE.

\section{How to cite this article:}

Navdeep Singh and Daljeet Singh. 2020. Effect of Plant Growth Promoting Bacteria on Seed Germination, Seedling Vigor and Growth Lagenaria siceraria (Molina) Standl. Int.J.Curr.Microbiol.App.Sci. 9(08): 1161-1168. doi: https://doi.org/10.20546/ijcmas.2020.908.128 